\title{
Symptomatic Orthotopic Ureterocele in a Dog
}

\author{
Rebeca Bastos Abibe, Cláudia Valéria Seullner Brandão, Geovane José Pereira, \\ Luciane dos Reis Mesquita \& Sheila Canevese Rahal
}

\begin{abstract}
Background: Ureteroceles are cystic dilatations of the terminal ureter and is a rare diagnosed condition in dogs. They can be classified as orthotopic when it is entirely within the bladder and the ureteral orifice emerges normally or ectopic if the ureteral orifice is not in the normal position in the trigone. Orthotopic are usually clinically silent. Ureterocele can contribute to lower urinary tract disease leading to infections and loss of the renal function. As long as this injury can arise slowly, it might be underdiagnosed in companion animals. This case aims to report a case of a bitch with diagnosed symptomatic orthotopic ureterocele efficacious surgical treatment.

Case: A 5-month-old female mixed breed was referred to the veterinary hospital, with a major complaint of urinary incontinence since the birth date after the first attendance in a colleague who have suspected of ureterocele considering ultrasound report of a vesicle of $1.4 \times 1.5 \mathrm{~cm}$ in lefts ureter bladder's insertion topography with ipsilateral hydroureter and renal dilatation. Beside the urinary dysfunction, the animal presented good general status and normal vital signs. Complete blood count and biochemical analysis were within normal ranges. A new ultrasound exam and Computerized Urotomography with contrast gave the definitive diagnosis of left orthotopic ureterocele with twisted hydroureter (proximal $1.29 \mathrm{~cm}$ and distally $0.98 \mathrm{~cm}$ ) and hydronephrosis $(3.32 \mathrm{~cm})$. The marsupialization was chosen scientifically based to correct the ureterocele and the patient presented good general condition since then with prompt improvement of clinical signs. The patient was submitted to serial image exams in six weeks following up to check the consequent urinary tract dilatation from the previous disease regression. After the last follow up animal received hospital discharge and was assessed twice in four months with normal measures of the urinary tract.

Discussion: Different from the most common insert point of this injury, this case report presents an orthotopic ureterocele which due to the clinical signals, could be diagnosed differently from the literature who have described most often ectopic or asymptomatic events. Corroborating with usual development of uretero vesical junction obstruction described, this patient also advanced to hydroureter, hydronephrosis and kidney parenchymal loss. Due to being uncommon in small animal routine, diagnosis and therapeutic recommendations are based on few veterinarian and mainly human data. The gold-standard diagnostic method is excretory urethrocystography with an intra-bladder image called "cobra-head" or a contrast cystic fill defect. When ectopic ureterocele is suspected, intra-venous contrast urography or Computerized urotomography are a thrustful choice. Surgical treatment is indicated in symptomatic and obstructive ureterocele. The planning was based in urotomography diagnosis of unilateral orthotopic left ureterocele, marsupialization technique was performed. Two days after the procedure, the patient returned maintaining the total enhancement of incontinence. During the image follow up made after the surgery was observed decrease of the dilatations and improvement of renal medullary cortical ratio. This case report raises the importance of counting uncommon diseases as differential diagnosis in the veterinarian routine. Also, the use of the correct image approach can lead to the definitive diagnosis and treatment.
\end{abstract}

Keywords: incontinence, urology, surgery, dog. 


\section{INTRODUCTION}

Urinary tract disease in companion animals is a significant excerpt of clinical care in veterinary hospitals $[8,12]$. Those injuries include surgical cases as obstructive feline lower urinary tract disease, complicated urolithiasis, ectopic ureter, vesicoureteral junction and ureteropielic junction stenosis, trauma-related dysfunction, such as bladder and urethra rupture, and ureterocele [12]. Surgical treatment is indicated when the patient shows loss of renal function and parenchyma, and electrolyte imbalance, leading to systemic changes [4].

Uncommon in veterinary medicine, ureterocele is cystic distension of the submucosa layer in the distal ureter [11], contributing to low urinary tract disease and progressive loss of the renal function [5]. Some classifications were proposed, but they are commonly named as the point of insertion of the ureter in the bladder: orthotopic and ectopic. Orthotopic or intravesical, the ureter is correctly implanted and ectopic when it is situated at the bladder neck or urethra [7,8,11].

Treatment consists in treating any concomitant infection and afterwards surgical excision of the defect [18]. Imaging follow up after the procedure is important to trail if dilatations and cortical-medullar ratio measurements are improving and so the prognosis [20].

This paper aims to describe the occurrence of a symptomatic orthotopic unilateral ureterocele causing obstruction of the urinary flow and its diagnosis, surgical therapeutic approach, as well as long term outcome.

\section{CASE}

A 5-month-old entire bitch, crossed breed, weighing $7.5 \mathrm{~kg}$ was referred to the veterinary hospital with urinary incontinence since the birth date. The patient received a previous diagnosis of ureterocele due to an intravesical sacculation in left ureter insertion topography. This report described a $1.4 \times 1.5 \mathrm{~cm}$ intravesical dilatation with hydroureter (proximal ureter: $1.4 \mathrm{~cm}$ and distal ureter: $0.7 \mathrm{~cm}$ ) besides renal pelvis amplification $(1.9 \mathrm{~cm})$ with corticomedullary ratio loss.

The animal was alert and conscious, presenting good general status, without signs of dehydration, good arterial pulse quality, and rosy mucous membrane. The patient presented urinary incontinence and no vulvar sign of estrus. Complete blood count showed no alterations (Hct: 39\%; Hb: $14.8 \mathrm{~g} / \mathrm{dL}$; RBC: 6,140,000 cels/ $\mu \mathrm{L}$ ) and mild leukocytosis $(924,900$ cels $/ \mu \mathrm{L})$ due to neutrophilia
$(18,900$ cels $/ \mu \mathrm{L})$. Serum urea $(40 \mathrm{mg} / \mathrm{dL})$ and creatinine $(0.89 \mathrm{mg} / \mathrm{dL})$ were within the specific parameters range. Urinalysis indicated mild bacteriuria with 15-20 leukocytes per camp, $\mathrm{pH}$ 8.0, urinary density above 1.050 and a cloudy aspect. The imaging exam corroborates with the previous report of hydronephrosis (rp: $3.32 \mathrm{~cm}$ ), hydroureter (pu: $1.29 \mathrm{~cm}$ and du: $0.98 \mathrm{~cm}$ ) and left ureterocele but with measurements increasing. Since this injury can occur associated with an ectopic ureter, a Computerized Urotomography was made and gave the diagnosis of left orthotopic ureterocele with hydronephrosis and contorted ipsilateral hydroureter (Figure 1). Initial treatment to urinary infection was prescribed with Amoxicillin Clavulanate ${ }^{1}[22 \mathrm{mg} / \mathrm{kg}$ PO q $12 \mathrm{~h}]$.

A surgical approach is the standard treatment for this injury. Methadone ${ }^{2}$ [Mytedom ${ }^{\mathrm{TM}} 10 \mathrm{mg} / \mathrm{ML}$ - $1.74 \mathrm{mg} / \mathrm{IM}]$ was given as pre-anesthetic medicine, induction with propofol ${ }^{2}$ [Provive $1 \%$ - $40 \mathrm{mg} / \mathrm{IV}$ ] associated with ketamine Ketamine hydrochloride ${ }^{3}$ $10 \%-8.7 \mathrm{mg} / \mathrm{IV}]$ and continuous infusion of fentany $\mathrm{l}^{4}$ [Fentanyl citrate $0,075 \mathrm{mg} / \mathrm{mL}$ - $10 \mu \mathrm{g} / \mathrm{kg} / \mathrm{IV}$ ] with isoflurane ${ }^{4}$ [Isoforine ${ }^{\mathrm{TM}} 1 \mathrm{~mL} / \mathrm{mL}$ ] to anesthetic maintenance. During the celiotomy, the urinary tract was inspected and the ureter insertion checked to confirm its correct position and urine was sterile collected to antibiogram. With the cystotomy, a cystic structure was visible at the probable left ureter insertion within the bladder mucosa (Figure 2). All the other structures of the urinary trigone were located - right ureter and urethra - and, catheters were inserted confirming the structure's position. An incision was made on the ureterocele with prompt urine drainage and insertion of a $6 \mathrm{~F}$ urinary catheter $\left(\text { Solidor }^{\mathrm{TM}}\right)^{5}$ was performed in the left ureter, catheter while in the contralateral side a $22 \mathrm{G}$ (Nipro Safelet ${ }^{\mathrm{TM}}$ ETFE Radiopaco 22G) ${ }^{6}$ was inserted due to the hydroureter (Figure 3). No other path was observed in the ureter insertion. Marsupialization technique was performed with 5-0 polyglactin 910 (QualTrus $\left.{ }^{\mathrm{TM}}\right)^{7}$ in two continuous pattern $180^{\circ}$ around the orifice (Figure 4). The bladder closure was given with 3-0 polyglactin $910^{7}$ in Cushing double pattern. All post-operative drugs were provided as prescribed, i.e. meloxicam ${ }^{1}[0.1$ $\mathrm{mg} / \mathrm{kg}$ PO q $24 \mathrm{~h}$ - for 5 days], omeprazole ${ }^{1}$ [ $1 \mathrm{mg} / \mathrm{kg}$ PO q $24 \mathrm{~h}$ ] and dipyrone ${ }^{8}[25 \mathrm{mg} / \mathrm{kg}$ PO q $8 \mathrm{~h}$ - for 5 days]. Immediately after surgery, the patient presented no more urinary incontinence improving its 


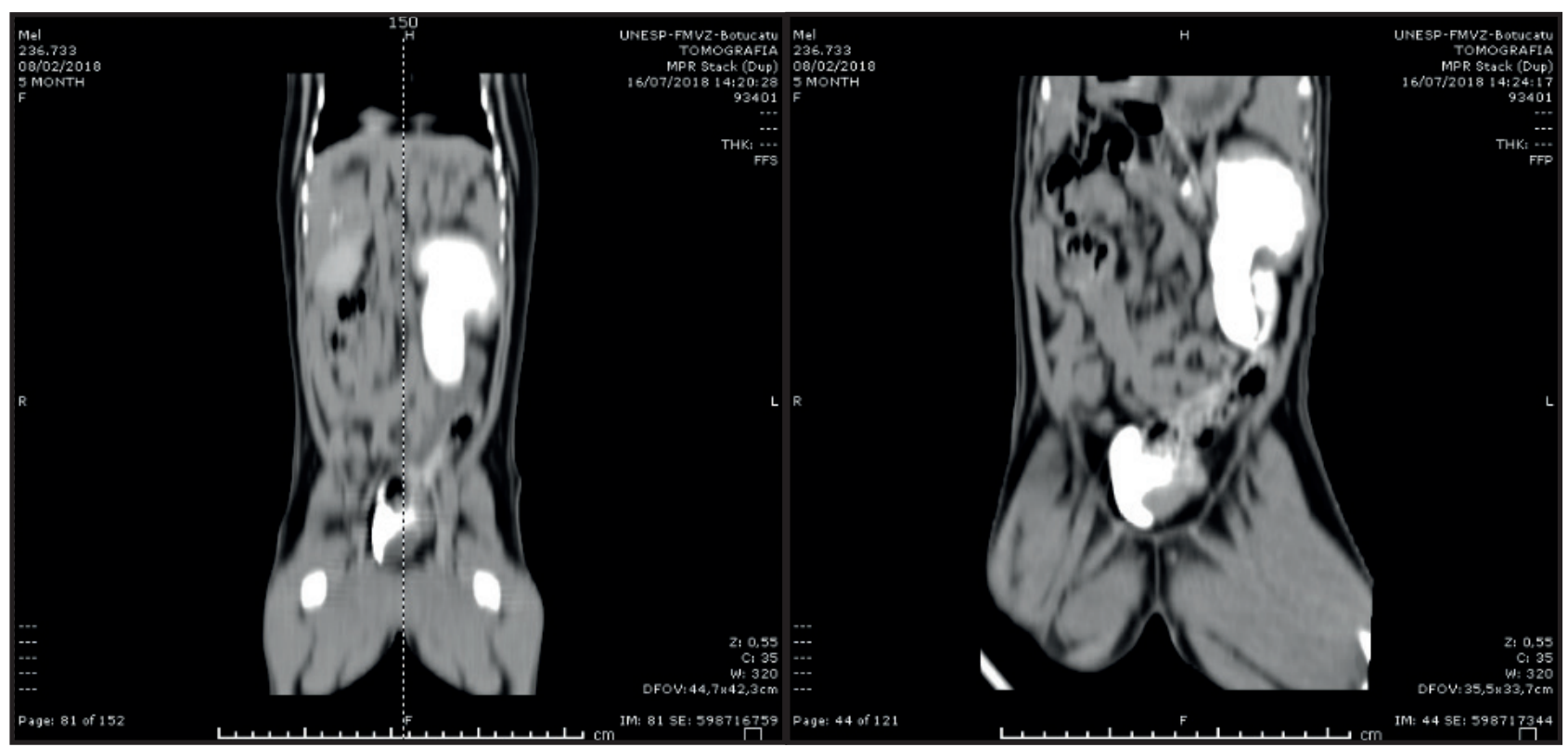

Figure 1. Contrasted urotomography pointing hydronephrosis and twisted hydroureter on the left side. Cystic contrast fills failure inside the bladder suggesting ureterocele.

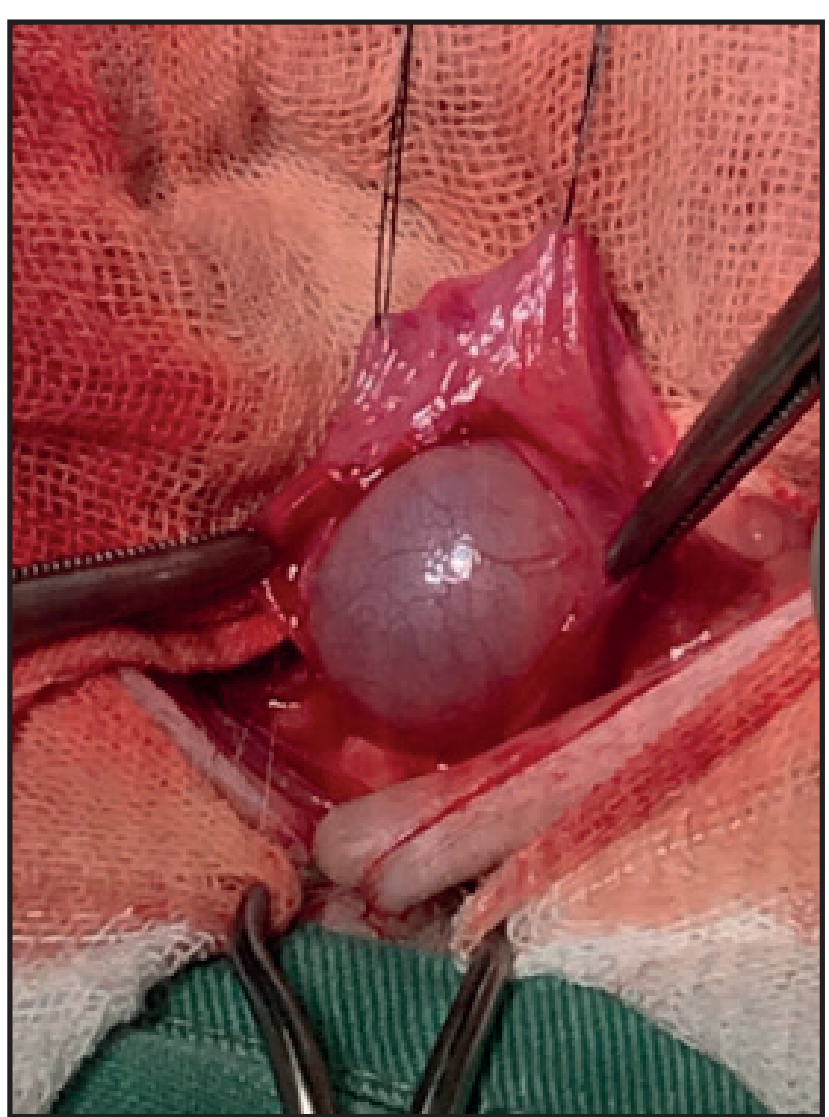

Figure 2. Intra-operatory image of bladder mucous cystic dilatation.

condition. It was assessed two days after surgery and urinary incontinence maintained total recovery. No amoxicillin-clavulanate resistant bacterial growth was

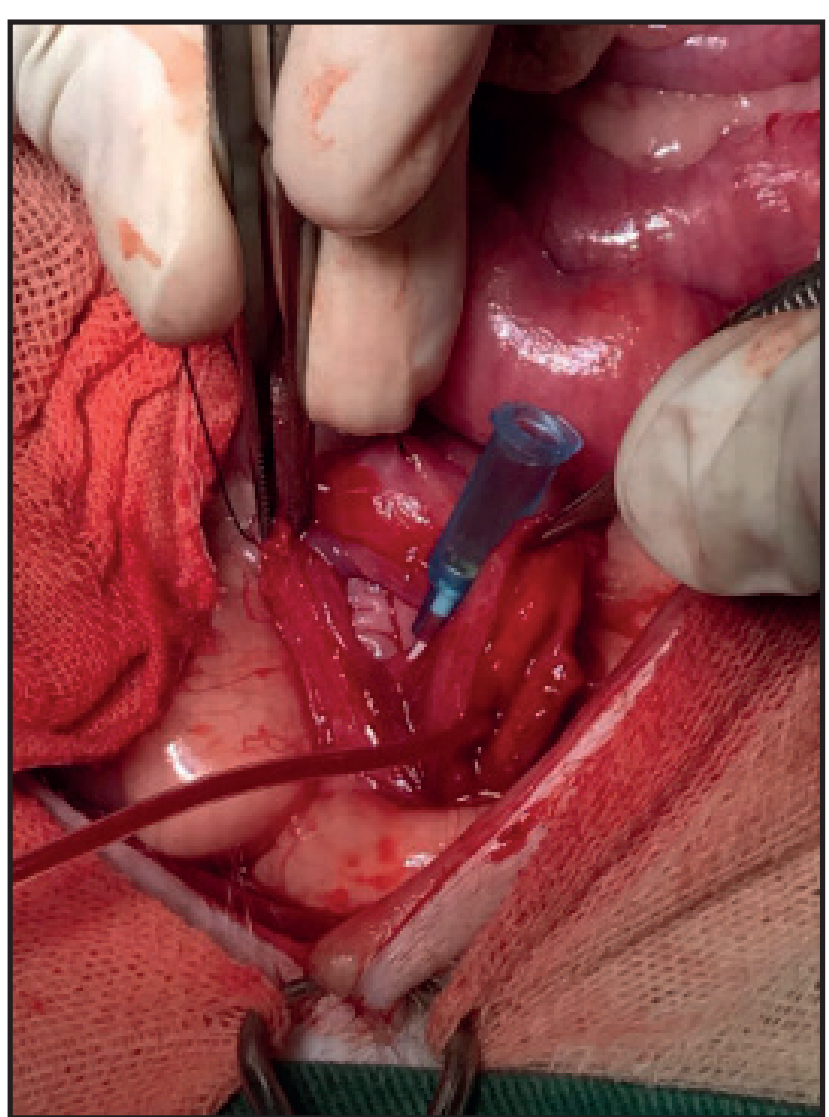

Figure 3. Intra-operatory image of both ureters catheterized to ostium delimitation. Left ureter with a $6 \mathrm{~F}$ urinary catheter due to hydroureter and the contralateral with a $22 \mathrm{G}$ venous catheter.

observed in urine and urinalysis was within species rate/value, so amoxicillin clavulanate ${ }^{1}$ was mantained [22 mg/kg PO q $12 \mathrm{~h}$ - for 7 days]. 


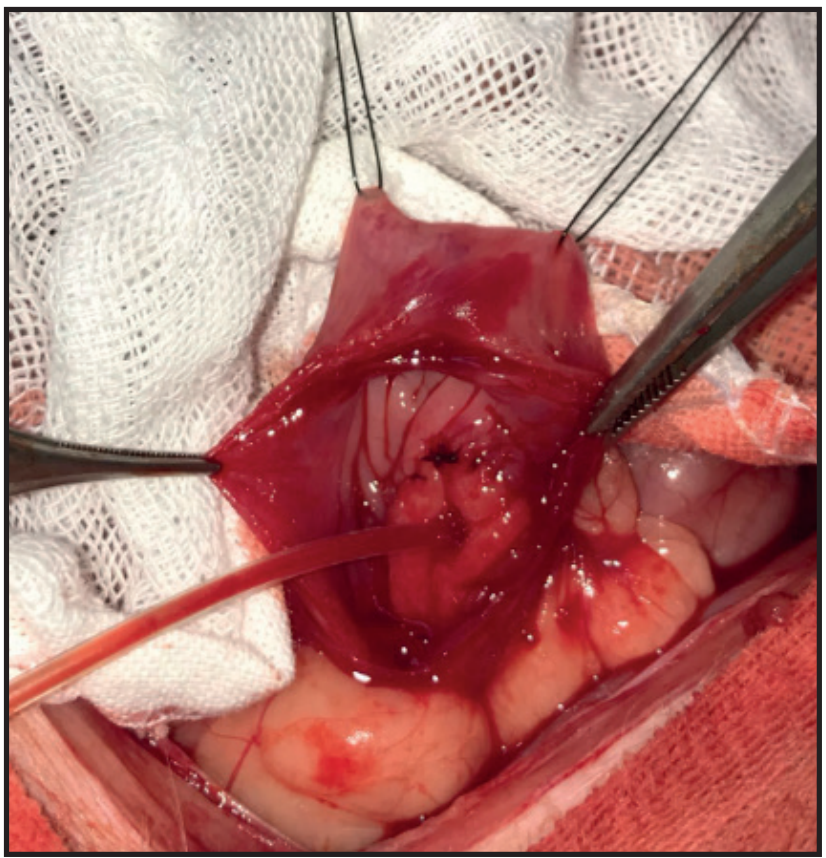

Figure 4. Marsupialization of ureterocele using double continuous $180^{\circ}$ pattern of suture.

Images follow-up was made monthly post-operative, on the first exam renal pelvis $(\mathrm{rp}: 1.99 \mathrm{~cm})$ and ureter dilatation (pu: $0.91 \mathrm{~cm}$ du: $0.48 \mathrm{~cm}$ ) shrinkage was observed but still showing a corticomedullar loss. In the next return could be observed a measurement decrease (rp: $0.97 \mathrm{~cm}$, pu: $0.63 \mathrm{~cm}$, du: $0.63 \mathrm{~cm}$ ) and corticomedullar ratio improvement. After three months the urinary tract dimension continues to reduce and the corticomedullar portion characterized.

\section{DISCUSSION}

Ureterocele is commonly described in human medicine [19] and uncommon when associated with veterinary medicine. Since ureteroceles are usually asymptomatic [2], the low rate of diagnosed cases in veterinary might be due to it [16]. Females are four to six times more affected and when compared, ectopic ureterocele is four times more often than orthotopic $[5,13]$. This paper describes a bitch diagnosed with ureterocele corroborating with the sex prevalence described in the literature contrasting with the orthotopic insertion of the ureter which is less cited than ectopic.

It is a congenital injury described by cystic distension of the submucosa layer in the distal ureter, mostly intramural in the bladder protruding through the vesical lumen $[2,8,10,11,17]$. It can also be known as unilateral or bilateral [11], and graduated based on the renal injury associated with reflux or urine flow obstruction aiming to define a patient's prognosis [3]. Etiology is unknown [8], yet several theories explain it using embryogenesis such as arrested myogenesis of the distal ureter; ureteral distention secondary to ureteral obstruction; reverse urine flow forcing the vesicoureteral canal; and persistence of Chwalle's membrane which separates ureter from common excretory duct $[4,17]$.

An ectopic ureterocele is usually related to urinary incontinence [2], similar to ectopic ureter [17]. Dispute to literature, the orthotopic location is frequently an accidental finding, this case reports a patient with urinary incontinence and not a silently intravesical ureterocele $[11,14]$. The expected clinical signals are urinary incontinence, dysuria, hematuria, urinary tract chronic infection and total or partial urinary clog [16]. As already discussed, urinary obstruction occurs with hydrostatic pressure changes and may lead to obstructive nephropathy with previously hydroureter, hydronephrosis and loss of renal parenchyma as it develops in this report $[2,15]$.

As cited and applied to this case, urotomography can be used to image diagnose an ureterocele with all the measurements, precisely diagnose of ectopia or not and evaluation of all the urinary tract organs and tissues remodeling being useful to the surgeon to surgery planning [2,7]. Ultrasonography is also a good and cheap tool in this injury [2]. Urethrocystography is the chosen method when the clinical wants to diagnose an ureterocele, the iodo contrast $\left(\right.$ RELIEV $\left.^{\circledR}\right)$ produces a "Cobra-head" image owning to a defect of intravesical contrast filling $[1,9,11]$. In the case of suspected ectopic ureterocele, the standard method is intravenous urography (OMNIPQUE ${ }^{\circledR}$ ) so the urethral catheter cannot mask the ureter insertion site [10]. Cystoscopy can be also used as a diagnostic method $[9,10]$.

Evaluation of urinary tract is important to identify concomitant conditions as hydroureter, hydronephrosis and parenchymal scan with possible loss of the ratio between the structures to establish the intensity of the vesicoureteral reflux and renal function [16].

Surgery is the treatment for ectopic and orthotopic ureterocele. To intravesical, the chosen technique is marsupialization $[5,8]$ as was utilized in this case report. In ectopic conditions, ureteral transaction and reimplantation within the bladder wall (neoureterostomy) is necessary with occlusion of the excised excerpt [6]. 
In brief, orthotopic ureterocele case reports are scarce in veterinary medicine and in medicine and this case report describes it in a symptomatic and unilateral appearance of the disease. This case report also shows that orthotopic ureterocele, although underdiagnosed, has to be listed as one of differential diagnosis in patients with dysuria and urinary incontinence. Corroborating with the known scientific data, surgical marsupialization is effective to correct the injury with favorable prognosis of restoration of normal urinary and renal function.

\section{MANUFACTURERS}

${ }^{1}$ Agener União Distribuidora de Medicamentos Ltda. São Paulo, SP, Brazil.
${ }^{2}$ União Química Farmacêutica Nacional S.A. São Paulo, SP, Brazil. ${ }^{3}$ Syntec do Brasil Ltda. Santana de Parnaíba, SP, Brazil.

${ }^{4}$ Cristália Produtos Químicos Farmacêuticos Ltda. Itapira, SP, Brazil.

${ }^{5}$ Well Lead Medical Co. Ltd. Guangzhou, GD, China.

${ }^{6}$ Nipro Medical Corporation Produtos Médicos Ltda. São Paulo, SP, Brazil.

${ }^{7}$ Johnson \& Johnson do Brasil Indústria e Comércio de Produtos para Saúde Ltda. São Paulo, SP, Brazil.

${ }^{8}$ Laboratório Bio-vet Ltda. Vargem Grande Paulista, SP, Brazil.

Acknowledgments. The authors thanks to the FMVZ-UNESP Botucatu Radiology Service for providing the radiographic images.

Declaration of interest. The authors report no conflicts of interest. The authors alone are responsible for the contents and writing of the paper.

\section{REFERENCES}

1 Albers P., Foster R.S., Bihrle R., Adams M.C. \& Keating M.A. 1995. Ectopic ureters and ureteroceles in adults. Urology. 45(5): 870-874.

2 Brovida C. 2014. Urogenital defects in dogs. Veterinary Focus. 24(1): 2-4.

3 Churchill B.M., Sheldon C.A. \& McLorie G.A. 1992. The ectopic ureterocele: a proposed practical classification based on renal unit jeopardy. Journal of pediatric surgery. 27(4): 497-500.

4 Grauer G.F. 2010. Manifestações clínicas dos distúrbios urinários. In: Nelson R.W. \& Couto C.G. (Eds). Small Animal Internal Medicine. 4.ed. Rio de Janeiro: Elsevier, pp.609-696.

5 Green T.A., Arble J.B., Chew D.J. \& Dudley R.M. 2011. Diagnosis and Management of Ureteroceles in Two Female Dogs. American Animal Hospital Association. 47(2): 138-144.

6 Hendren W.H. \& Mitchell M.E. 1979. Surgical correction of ureteroceles. The Journal of Urology. 121(5): 590-597.

7 Lamb C.L. \& Gregory S.P. 1998. Ultrasonographic findings in 14 dogs with ectopic ureter. Veterinary Radiology \& Ultrasound. 39(3): 218-223.

8 Lautzenhiser S.J. \& Bjorling D.E. 2002. Urinary incontinence in a dog with an ectopic ureterocele. Journal of the American Animal Hospital Association. 38(1): 29-32.

9 McLoughlin M.A. 2002. Cystoscopic evaluation of the lower urinary tract. In: Proceedings of the $30^{\text {th }}$ Annual Surgical forum, 37 th Annual Scientific Meeting from the American College of Veterinary Surgery Symposium. (San Diego, USA). pp.350-354.

10 McLoughlin M.A. \& Chew D.J. 2000. Diagnosis and surgical management of ectopic ureters. Clinical Techniques in Small Animal Practice. 15(1): 17-24.

11 McLoughlin M.A., Hauptman J.G. \& Spaulding K. 1989. Canine ureteroceles: a case report and literature review. Journal of American Animal Hospital Association. 26(6): 699-706.

12 Pearson H. \& Gibbs C. 1971. Urinary abnormalities in the dog. Journal of Small Animal Practice. 12(2): 67-82.

13 Rickwood A.M.K., Reiner I., Jones M. \& Pournaras C. 1992. Current management of duplex-system ureteroceles: experience with 41 patients. British Journal of Urology. 70(2): 196-200.

14 Scott R.C., Greene R.W. \& Patnaik A.K. 1974. Unilateral ureterocele associated with hydronephrosis in a dog. Journal of American Animal Hospital Association. 10: 126-132.

15 Snyder H.M. \& Johnston J.H. 1978. Orthotopic ureteroceles in children. The Journal of Urology. 119(4): 543-546.

16 Stiffler K.S., McCrackin Stevenson M.A., Mahaffey M.B., Howerth E.W. \& Barsanti J.A. 2002. Intravesical ureterocele with concurrent renal dysfunction in a dog: A case report and proposed classification system. Journal of American Animal Hospital Association. 38(1): 33-39.

17 Sutherland-Smith J., Jerram R.M., Walker A.M. \& Warman C.G.A. 2004. Ectopic ureters and ureteroceles in dogs: presentation, cause, and diagnosis. Compendium. 26(4): 303-310. 
18 Takiguchi M., Yasuda J., Ochiai K., Morita Y. \& Hashimato A. 1997. Ultrasonographic appearance of orthotopic ureterocele in a dog. Veterinary Radiology \& Ultrasound. 38(5): 398-399.

19 Uson A.C., Lattimer J.K. \& Melicow M.M. 1961. Ureteroceles in infants and children: a report based on 44 cases. Pediatrics. 27(6): 971-983.

20 Wang M.H., Greenfield S.P., Williot P. \& Rutkowski J. 2008. Ectopic ureteroceles in duplex systems: long-term follow up and 'treatment-free' status. Journal of Pediatric Urology. 4(3): 183-187. 